\title{
Effects of Arbuscular Mycorrhizal Fungi (AMF) and Bacterial Strains on Orobanche crenata Forsk, on Faba Bean
}

\author{
Mohammed Mahgoub Hassan ${ }^{1, *}$, Rania Alrasheed Abakeer ${ }^{2}$ \\ ${ }^{1}$ Environment and Natural Resources Research Institute, National Centre for Research, Khartoum, Sudan \\ ${ }^{2}$ College of Agricultural Studies, Sudan University of Science and Technology, Khartoum, Sudan \\ Corresponding Author: mohkadis@yahoo.com
}

Copyright (C) 2013 Horizon Research Publishing All rights reserved.

\begin{abstract}
Faba bean (Vicia faba L.) is an important grain legume crop in many countries and is severely constrained by infection by the weedy root parasite Orobanche crenata (crenate broomrape). The present work was carried out to evaluate the potential of arbuscular mycorrhiza fungi (AMF) and bacterial strains to suppress Orobanche crenata on faba bean. Orobanche infestation was influenced by the bacteria, AM fungi and the time the observation was made. Faba bean inoculated with the combination between bacterial strains (B2) \{TAL 1399 plus A. brasilense\}, B3 (TAL 1399 plus BMP $\{$ Bacllius megathirium var phosphaticum $\}$ ) alone or in combination with mycorrhiza fungi (AM) were completely inhibited Orobanche plant emergence. Time at which highest rate of Orobanche emergence occurred on faba bean was significantly delayed with AM fungi incorporated with each of the bacterial strains (B1, B2 and B3). The highest increment of faba bean shoot was obtained when AM fungi was incorporated with bacterial strains B3 as compared to control. Mycorrhizal (AM) fungi plus bacterial B2 root colonization were positively correlated with total dry matter of faba bean. With respect to nodule numbers results displayed that faba bean inoculated with bacterial B2 alone or in combination with AM fungi sustained the highest nodule numbers as compared to both controls. Adoption of an integrated approach encompassing AM fungi and bacteria inoculation may provide a novel, cheap and easy method to apply for $O$. crenata control under subsistence low-input farming systems.
\end{abstract}

Keywords AM Fungi, Bacterial Strains, Faba Bean, Orobanche Crenata

\section{Introduction}

Studies on microbial interactions in the mycorrhizosphere have focused on exotic populations of beneficial soil microorganisms, such as Azospirillum (Subba Rao et al.,
1985), plant growth promoting rhizobacteria (PGPR) (15) and phosphate-solubilizing bacteria (21). Relationships between native soil microbe communities and AM fungi in control parasitic weeds have received less attention. Arbuscular mycorrhizal (AM) fungi are soil-borne microorganisms living symbiotically with most land plants and in most ecosystems (20). Arbuscular mycorrhizal fungi (AMF) play a key role in facilitating nutrient uptake by crops in low-input farming systems. Some bacterial populations, called mycorrhiza helper bacteria, have beneficial effects on AMF growth not only by improving mycorrhizal root colonization and stimulating extraradical hyphal growth but also by facilitating AMF spore germination (9). The latter effect has been shown for Actinomycetes (5, 17), Pseudomonas and Corynebacterium (14), and Bacillus spp. (24).

Strigolactones characterized germination stimulants of the parasitic plants Striga and Orobanche, were isolated and characterized as active molecules on spore germination, hyphal branching, and growth of AM fungi $(1,3)$. In Striga hermonthica it was proposed that strigolactones act as elicitors of ethylene biosynthesis, leading to subsequent seed germination (13). Recently, strigolactones have been identified as a new class of plant hormones regulating shoot branching, suggesting their presence in above-ground plant organs (8). Furthermore, some rhizosphere bacteria promote plant development and seed germination. This ability should be given serious attention, because micro- propagated material is being used increasingly in commercial crops. AMF fungi usually enhance nodulation and nitrogen fixation in legumes, but the extent of these effects depends on AMF species (22).

Broomrape seed germination occurs only in response to a chemical signal from the host root. Before germination, broomrape seeds must undergo conditioning under suitable temperature and moisture conditions. The conditioning phase may range from five to 14 days, depending on the species. Following the conditioning phase, the seed produces a 'germ tube' or radicle in response to a chemical stimulant 
from the host root. The stability of the chemical stimulant is very short-lived in the soil (18). Management of broomrapes is often difficult due to several reasons. These include the high amount of seeds production, viability of seeds in the soil over several years, lack of seed germination in the absence of a chemical trigger from a suitable host, vigorous growth habit after emergence, and close association with the host crop. Several means for managing broomrapes have been tried over the years, albeit with somewhat limited effectiveness. Therefore, research could now be aimed to optimize the use of AM fungi and PGPBs and their interaction on the Orobanche crenata in faba bean.

\section{Materials and methods}

\subsection{Biological Materials}

Faba bean seeds variety Silaim were surface sterilized (ethanol, 70\%, v:v, $2 \mathrm{~min}$ ) and planted in plastic pots filled with a steam-pasteurized mixture of sand and sandy-loam soil $(1: 1, \mathrm{v}: \mathrm{v})$.

\subsection{AMF}

AMF was provided by Dr. tilal. AMF comprising the combination between Glomus intraradices, G. clarodium and Paraglomus spp. The species were propagated in association with Sudan grasses plants under standard pot culture conditions.

\subsection{Bacterial Strains}

Free-living nitrogen fixing microorganism, belonging to the genera Azospirilium, symbiotic nitrogen fixing microorganism, belonging to the genera Rhizobium in addition to phosphorus solubilizing microorganism belong to genera Bacillus, were assayed. The bacterial strains were obtained from the Environment and Natural Resources Research Institute (ENRRI), the National Centre for Research. Meat peptone agar medium was used for growth of bacterial strains. Counts of the developing colonies were expressed as Colony Forming Unit (CFU) per ml.

\subsection{Orobanche Seeds Collection}

Orobanche crenata seeds, used in this study, were collected from parasitic plants growing under faba bean in 2006 at Shendi Research Station Farm during the winter season.

\subsection{Pot Experiment}

The experiments were conducted at College of Agricultural Studies Sudan University of Science and Technology during November 2010 - January 2011 in a greenhouse. Eight treatments of bacterial strains and AM fungi were used. All treatments were replicated four times. In this experiment, a soil mixture was made of sandy-loam soil and sand $(1: 1 \mathrm{v} / \mathrm{v})$ then placed in plastic bags $(19 \mathrm{~cm}$ diameter) with drainage holes at the bottom. Six milligrams of Orobanche seeds were thoroughly mixed with the top 6 $\mathrm{cm}$. soil in each plastic pot of the treatments receiving Orobanche. Emerged faba bean seedlings were thinned after two weeks from sowing. The time of emergence of the first Orobanche shoots in the relevant pots was recorded. Five grams of AM fungal inoculum were mixed with the top $6 \mathrm{~cm}$ of pot soil in the relevant treatments. Aliquots of the respective bacterial suspensions ( $15 \mathrm{ml}$ each) were injected, within the root zone, in each pot. Subsequent irrigations were made every 2 days. Faba bean was thinned to two plants per pot at 10 days after sowing.

Orobanche infested and uninfested controls were included in each experiment for comparison. Numbers of Orobanche shoots emerged per pot were recorded at 6,7 and 8 weeks after plant emergence (WAE). Faba bean plant height was measured at 4,8 , and 10 weeks after emergence. Data collected on numbers of nodules, dry weights of faba bean shoot and roots were recorded at the end of the experiment 11 WAE.

\subsection{Statistical Analysis}

Data from the greenhouse experiments were transformed to $\log$ square root $(\mathrm{x}+0.5)$ in which $\mathrm{x}$ is the number of Orobanche plants/ pot and then subjected to analysis of variance (ANOVA). Means were tested for significance by LSD at 5\%. Data on faba bean height, number of nodules and dry weight were subjected to analysis of variance. Means were tested for significance by LSD at $5 \%$.

\section{Results}

Result showed that AM fungi and bacterial strains, reduced emergence of the parasite. At six weeks after sowing (WAE) Orobanche emergence was only observed on the un-inoculated faba bean, B1 and AM fungi (Fig. 1) At seven WAE, Striga emergence increased, substantially, and was heighest on the unfertilized un-inoculated control. In among all treatments bacteria B1 was the least effective. While at eight WAE, the un-inoculated faba bean sustained the highest infestation (1.5 plants/ pot). Faba bean treated with B2, B3, AM plus B1, AM plus B2 and AM plus B3 displayed no Orobanche emergence. Combinations between AM fungi and bacteria were, invariably, more suppressive to the parasite emergence than each treatment alone (Fig. 1). Time at which highest rate of Orobanche emergence occurred on faba bean was significantly delayed with AM fungi incorporated with each of the bacterial strains (B1, B2 and B3) (Fig.1). However, the combination between B1 plus AM fungi was more suppressive than each alone. In among all treatments, the combination between AM fungi with each of bacterial $\mathrm{B} 2$ or $\mathrm{B} 3$ and $\mathrm{B} 1$ were the most inhibitory. 


\subsection{Effects on Plant Height}

The untreated Orobanche free crop displayed the tallest plants $(37 \mathrm{~cm}$.) at 10 WAE. Unchecked Orobanche infestation reduced crop height by $19 \%$. Also, results displayed that all treatments increased plant height as compared to infested control. The highest increment of faba bean shoot was obtained when AM fungi was incorporated with bacteria B3 as compared to infested control. It increased plant height by $33 \%$ (Fig. 2).

\subsection{Effects on Plant Dry Matter}

Results displayed that the total dry weight of faba bean plants parasitized by Orobanche was lower than that of uninfested control plants (Fig 3). Results displayed that all treatments increased faba bean dry matter as compared to the infested control. The highest total dry weight was obtained when faba bean plants were inoculated with AM fungi incorporated with bacteria $\mathrm{B} 2$ as compared to the infested control and other treatments. Plant inoculated with AM fungi plus bacteria $\mathrm{B} 1$ was found to be two times greater of shoot dry weight than that of the infested control (Fig 3). With respect to root dry weight, results showed that the combination between AM fungi plus B2 sustained the highest weight as compared to infested control (Fig 3).

Faba bean inoculated with the combination between B2 plus AM fungi sustained the highest percent reduction of $O$. crenata emergence $(100 \%)$ and increased total dry matter of faba bean over the infested control by $38 \%$ ( Fig 1 and Fig. $3)$.

\subsection{Effects on Nodules Number}

With respect to nodule numbers results displayed that faba bean inoculated with bacterial B2 alone or in combination with AM fungi sustained the highest nodule numbers as compared to un-infested and infested controls. They increased nodules number by and $50-79 \%$, respectively as compared to the infested control (Fig. 4).

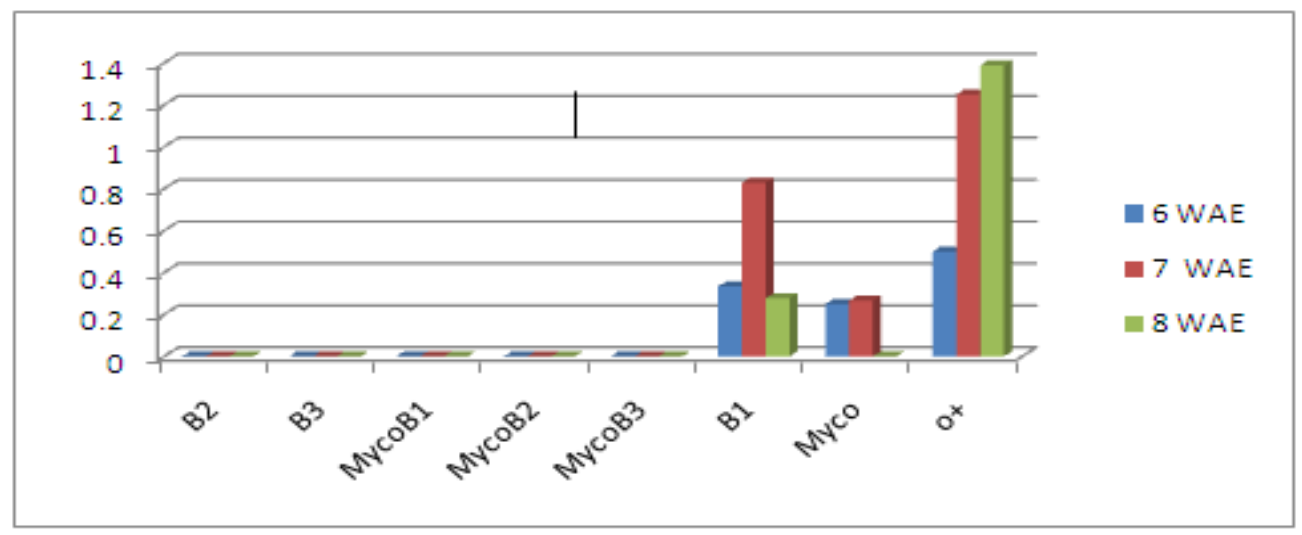

Keys:

B1: Bacteria 1 (TAL 1399); B2: bacteria 2 (TAL 1399+Ab: Azospirillium brasilense); B3: Bactria 3 (TAL 1399+BMP: Bacllius megathirium var. phosphaticum); Myco: (Mycorrhizae); O+: Control with Orobanche. Vertical bar indicates. Least Significant Difference (LSD) test at $\mathrm{P}<5 \%$.

Figure 1. Effects of bacterial strains and AM fungi on Orobanche crenata incidence on faba bean.

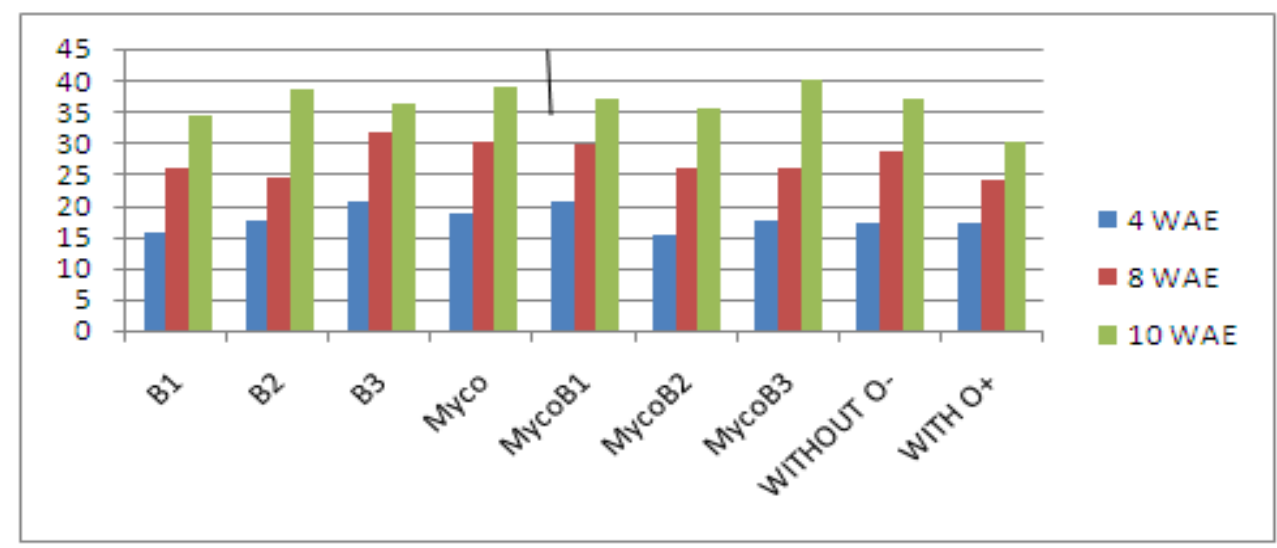

Keys:

B1: Bacteria 1 (TAL 1399); B2: bacteria 2 (TAL 1399+Ab: Azospirillium brasilense); B3: Bactria 3 (TAL 1399+BMP: Bacllius megathirium var. phosphaticum); Myco: (Mycorrhizae); O+: Control with Orobanche; O-: control without Orobanche. Vertical bar indicates LSD

Figure 2. Effects of bacterial strains and AM fungi on faba bean plant height. 


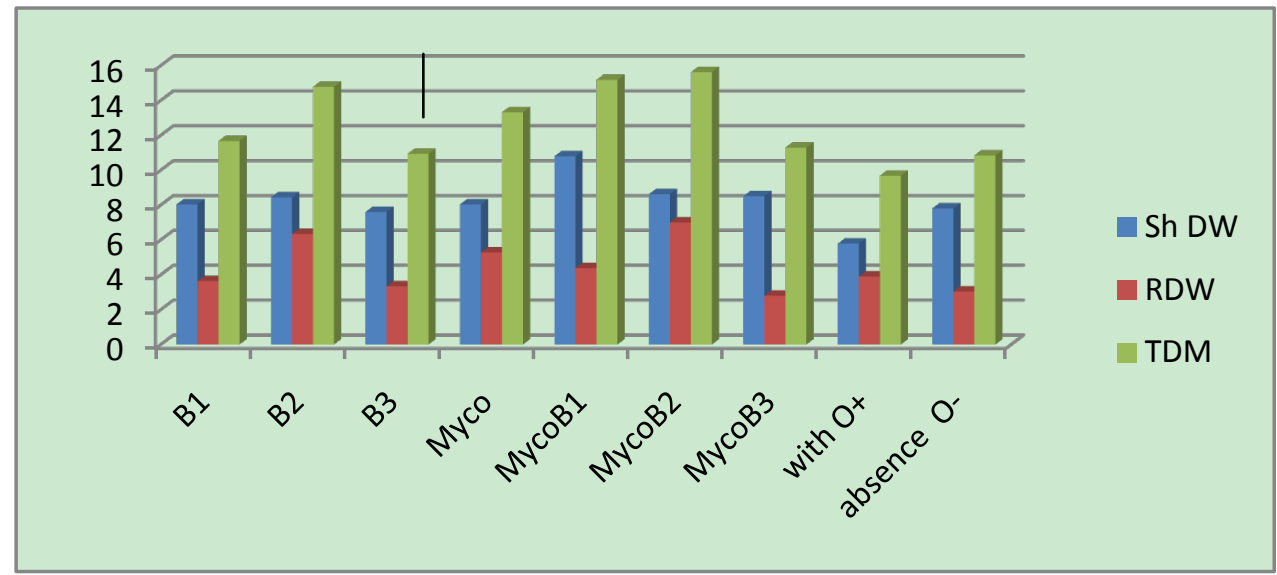

Keys:

B1: Bacteria 1 (TAL 1399); B2: bacteria 2 (TAL 1399+Ab: Azospirillium brasilense); B3: Bactria 3 (TAL 1399+BMP: Bacllius megathirium var. phosphaticum); Myco: (Mycorrhizae); O+: Control with Orobanche; O-: control without Orobanche . Vertical bar indicates LSD

Figure 3. Effects of bacterial strains and AM fungi on faba bean plant biomass.

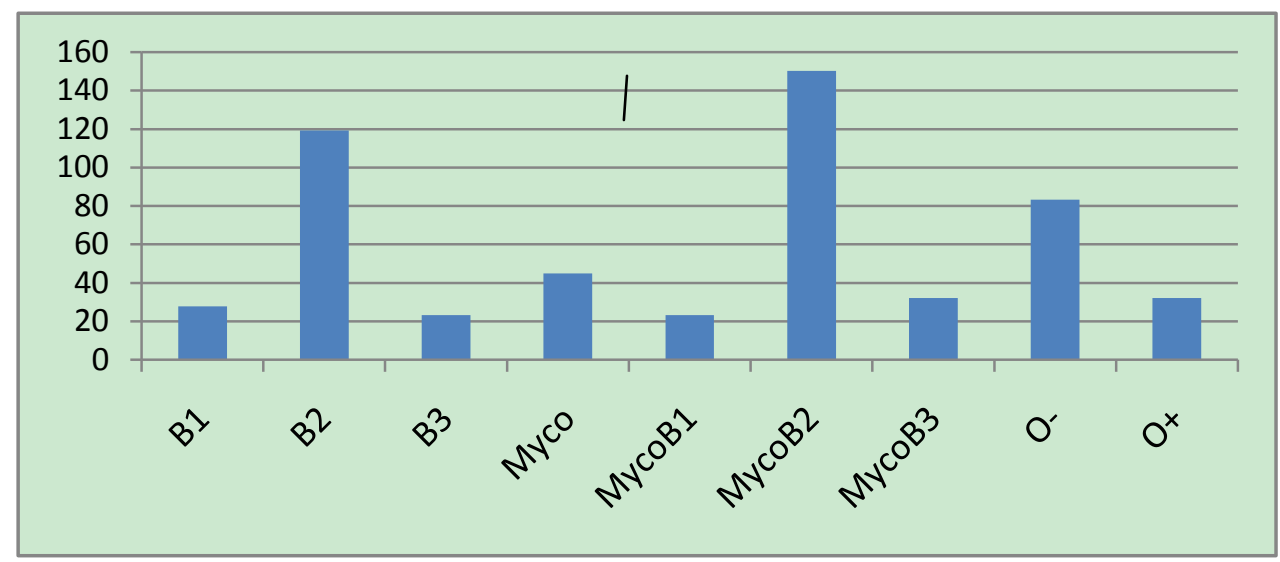

\section{Keys:}

B1: Bacteria 1 (TAL 1399); B2: bacteria 2 (TAL 1399+Ab: Azospirillium brasilense); B3: Bactria 3 (TAL 1399+BMP: Bacllius megathirium var. phosphaticum); Myco: (Mycorrhizae); O+: Control with Orobanche; O-: control without Orobanche . Vertical bar indicates LSD

Figure 4. Effects of bacterial strains and AM fungi on faba bean nodules number.

\section{Discussion}

Plant growth-promoting rhizobacteria are commonly found in the rhizosphere (adjacent to the root surface) and may promote plant growth via several diverse mechanisms, including the production or degradation of the major groups of plant hormones that regulate plant growth and development. Plant hormones [abscisic acid (ABA), auxins, cytokinins (CKs), ethylene, gibberellins (GAs), jasmonic acid (JA), salicylic acid (SA)] regulate multiple physiological processes including root initiation, elongation, architecture and root hair formation (7).

Parasitic plants are among the most problematic weeds that are responsible for major losses to many crops. Early growth stages, such as seed germination stimulated by host root exudates and tubercle development, are key phases for the development of these parasites. Inhibition of these early phases by naturally occurring compounds could be a general strategic option for management of parasitic plants (23).
Strigolactones induce hyphal branching in AM fungi at very low concentrations, suggesting a highly sensitive perception system for strigolactones present in AM fungi. Without the knowledge about the biology of the parasitic weeds by the farmers and basic preventive measures such as hygiene and seed quality control no control strategy will be successful, however.

Both AM fungi and parasitic weeds are attracted to the host roots by means of strigolactones (17). Better nutritive status in mycorrhizal plants could down-regulate the strigolactone exudation and, as a consequence, the autoregulation of further mycorrhizal colonies. The fact that several groups have reported that AM fungi can reduce Striga infection of sorghum and maize $(10,12)$. The effect was ascribed partly to improved crop performance owing to enhanced nutrient uptake by the successfully colonized roots, and partly to a reduction or delay in Striga germination and emergence. This may be due to decreased in germination stimulant formation after mycorrhizal colonization. 
Mycorrhizal root colonization was positively correlated with total dry matter of faba bean.

Similarly, some Rhizobium leguminosarum strains have been reported to induce defence against $O$. crenata in pea through activation of the oxidative process, and production of possible toxic compounds, including phenolics (6). Improved nutrient status as a consequence of mycorrhizal and bacteria colonization can also result in enhanced protection against pathogens (21). The inhibitory effects of the bacterial strains applied on faba bean could be attributed to a direct effect of the bacteria on the seed or indirectly through production of chemical (s) that is/are i) toxic to the seeds ii) inhibitors of ethylene biosynthesis iii) inhibitors of ethylene action iv) promoters of ethylene deactivation and $v$ ) promoters of ethylene biosynthesis (25). Allen (2) reported that legumes (Fabaceae) in collaboration with rhizobia make the largest contribution into $\mathrm{N}$ balance in natural and agricultural ecosystems. Suppression of Striga by nitrogen is consistent with several reports. Nitrogen curtails production of germination stimulants by host root exudates (26). Moreover, Muller-Stover and Kroschel (6) found that in vitro and in root chambers, germination of $O$. crenata seeds was decreased after inoculation with Ulocladium botrytis Preuss. Boari and Vurro (4) observed a $60 \%$ reduction in the number and weight of emerging $O$. ramosa shoots, and also a $70 \%$ reduction in the number of tubercles attached to tomato roots after application of Fusarium oxysporum and F. solani isolates in a plastic-bag system. The reduction in Orobanche seed germination by Fusarium isolates may be due to the production of toxic metabolites (27). In conformity with these results, Muller-Stover and Kroschel (6) found that dry matter accumulation of faba bean was significantly increased by treatment with $U$. botrytis compared with Orobanche-infected control. Also, Shabana et al.(19) observed an increase in sunflower dry weight as a result of treatments with $F$. oxysporum. Furthermore the present work clearly indicated that the bacterial strains employed are plant growth promoters. They relieve a portion of the growth retardation caused by the parasitic infestation of $O$. crenata. Hassan et al (26) reported that the bacteria increased sorghum plant height and biomass. Several reports showed that fertilizers, mainly phosphorus and nitrogen, lead to significant reductions in infestation of host crops by Striga, Orobanche and Phelipanche and the reduced infestation appears to be linked with alteration in strigolactone production (27). At least a considerable delay in Orobanche infestation could be displayed on inoculation of faba bean with bacteria and AM fungi. Delayed infestation by the parasite was reported to cause less damage than early infestations (28). Adoption of an integrated approach encompassing AM fungi and bacterial strains inoculation may provide a novel, cheap and easy method to apply for $O$. crenata control under subsistence low-input farming systems.

\section{REFERENCES}

[1] Meyer J, and Linderman R.G. (1986). respose of subterranean cloer to dual inoculation with vesicular-arbuscular mycorrhizal fungi and plant growth promoting bacterium, Psudomonas putida. Soil Biol. Biochem. 18:185-190.

[2] Toro, M, Nedialkova, K, Azc'on R and Barea JM (1996). Establishment of two rock phosphate- solubilizing bacteria in the rhizosphere of mycorrhizal onion plants and their effect on plant growth in a microcosm. In Mycorrhizas in Integrated Systems from Genes to Plant Development. Eds. C Azc'on-Aguilar and J M Barea. pp 665-668. European Commission, Directorate-General XII, Science, Research and Development, Brussels, Belgium.

[3] Smith, S.E., Read, D.J., (1997). Mycorrhizal Symbiosis. Academic Press, London.

[4] Gryndler, M., Hrselova, H. and Striteska D. (2000). Effect of soil bacteria on hyphal growth of the arbuscular mycorrhizal fungus Glomus claroideum. Folia Microbiol. 45:545-551.

[5] Carpenter-Boggs, L., T. E. Loynachan, and P. D. Stahl. (1995). Spore germination of Gigaspora margarita stimulated by volatiles of soil-isolated Actinomycetes. Soil Biol. Biochem. 27:1445-1451.

[6] Muller-Stover D. and Kroschel J. (2005). The potential of Ulocladium botrytis for biological control of Orobanche spp. Biol Cont 33:301-306.

[7] Mayo, K., Davis, R. E. and Motta J. (1986). Stimulation of germination of spores of Glomus versiforme by spore-associated bacteria. Mycologia 78:426-431.

[8] Xavier, L. J. C., and Germida, J. J. (2003). Bacteria associated with Glomus clarum spores influence mycorrhizal activity. Soil Biol. Biochem. 35:471-478.

[9] Akiyama K, Matsuzaki K, Hayashi H. (2005). Plant sesquiterpenes induce hyphal branching in arbuscular mycorrhizal fungi. Nature 435, 824-827.

[10] Besserer A, Be' card G, Jauneau A, Roux C, Se ' jalon-Delmas N. (2008). GR24, a synthetic analog of strigolactones, stimulates the mitosis and growth of the arbuscular mycorrhizal fungus Gigaspora rosea by boosting its energy metabolism. Plant Physiology 148, 402-413.

[11] Logan, D. C., Stewart, G. R. (1991). Role of ethylene in the germination of the hemiparasite Striga hermonthica. Plant Physiology 97: 1435-1438.

[12] Gomez-Roldan V, Fermas S, Brewer PB, et al. 2008. Strigolactone inhibition of shoot branching. Nature 455, 189-194.

[13] Valdenegro M, barea jm, azcòn R, (2001). Influence of arbuscular mycorrhizal fungi, rhizobium meliloti strains and pgpr inoculation on the growth of medicago arborea used as model legume for revegetation and biological reactivation in a semi-arid Mediterranean area. Plant growth regul, 34: 233-240.

[14] Parker, C., and Riches, C. R. (1993). Parasitic Weeds of the World: Biology and Control. CAB International, Wallingford, 


$$
\text { UK. pp332. }
$$

[15] Dodd I.C. (2009) Rhizosphere manipulations to maximize "crop per drop" during deficit irrigation. Journal of Experimental Botany, 60, 2454-2459.

[16] Vurro M, Boari A, Pilgeram AL and Sands DC (2006). Exogenous amino acids inhibit seed germination and tubercle formation by Orobanche ramosa (Broomrape): potential application for management of parasitic weeds. Biol Cont $36: 258-265$

[17] Yoneyama K., Xie X., Yoneyama K., Takeuchi Y. (2009). Strigolactones; structures and biological activities. Pest Manag. Sci.65:467-470.

[18] Gworgwor, N.A. \& Weber, H.C. (2003) Arbuscular mycorrhizal fungi-parasite-host interaction for the control of Striga hermonthica (Del.) Benth. in sorghum [Sorghum bicolor (L.) Moench]. Mycorrhiza, 13, 277-281.

[19] Lendzemo Vw, Kuyper Tw, Matusova R, Bouwmeester Hj \& Van Ast A (2007) Colonization by arbuscular mycorrhizal fungi of sorghum leads to reduced germination and subsequent attachment and emergence of Striga hermonthica. Plant Signalling Behaviour 2, 1-5.

[20] Mabrouk Y, Zourgui L, Sifi B, Delavault P, Simier P, Belhadj O (2007). Some compatible Rhizobium leguminosarum strains in peas decrease infections when parasitised by Orobanche crenata. Weed Res., 47: 44-53.
[21] Borowicz, V.A., 2001. Do arbuscular mycorrhizal fungi alter plant-pathogen relations?. Ecology 82, 3057-3068.

[22] Allen O. N., Allen E. K., 1981. The Leguminosae. A source book of characteristics, uses and nodulation. Wisconsin: Univ. Wisconsin Press, 800 p.

[23] Boari A and Vurro M. (2004). Evaluation of Fusarium spp. and other fungi as biological control agents of broomrape (Orobanche ramosa). Biol. Cont 30:212-219.

[24] Zonno, M.C., and Vurro, M. (2002). Inhibition of germination of Orobanche ramosa seeds by Fusarium toxins. Phytoparasitica 30:519-524.

[25] Imaseki, H. 1991. The biochemistry of ethylene biosynthesis. In: The Plant Hormone Ethylene (Mattoo, A.K. and Suttle, J. C. eds) pp. 1-21.CRC Press. Boca Raton USA.

[26] 26 Delft, G. J.; VAN, A. 1997. Root architecture in relation to avoidance of Striga hermonthica infection. Ph.D. Thesis, University of York, Tork, UK.

[27] Shabana YM, M"uller-Stover D and Sauerborn J (2003). Granular Pesta formulation of Fusarium oxysporum f.sp. orthoceras for biological control of sunflower broomrape: efficacy and shelf-life. Biol. Cont 26:189-201

[28] Hassan, M. M., M. E. Abdel gain and A. G. T. Babiker, (2009). Management of Striga hermonthica in sorghum using soil rhizosphere bacteria and host plant resistance. Int. J. Agric. Biol., 11: 367-373. 